\title{
O jogo como procedimento avaliativo para as aprendizagens Matemáticas 9
}

Meire Nadja Meira de Souza

Geraldo Eustáquio Moreira

\section{Resumo}

Este artigo apresenta o desafio de investigar o potencial do jogo como procedimento de avaliação formativa para as aprendizagens matemáticas. $\mathrm{O}$ estudo possui abordagem qualitativa com observação participante delimitada pelo estudo de caso de seis estudantes, no cenário de uma escola pública de Ceilândia - Distrito Federal, buscando responder à problemática: como tornar o jogo num procedimento avaliativo que promova as aprendizagens matemáticas numa turma do $3^{\circ}$ ano do Ensino Fundamental? O estudo de caso oportunizou a utilização de diferentes fontes de evidência: a observação participante, os registros de áudio e vídeo durante as proposições dos jogos e o diário de campo. A relevância em promover a avaliação formativa no contexto de jogos reside no fato de seu potencial lúdico propiciar possibilidades de elaboração de aprendizagens e se constituir em desafio que estimula a construção de conceitos matemáticos. A pesquisa buscou colocar os estudantes como protagonistas de sua própria aprendizagem, favorecendo manifestar, de forma espontânea, os conhecimentos construídos durante as aulas. $\mathrm{O}$ aporte teórico propiciou o pensar sobre a importância do jogo na produção do conhecimento matemático considerando a prática do feedback, pelo docente e por pares, como importante instrumento de ativação dos processos cognitivos e metacognitivos. Os resultados apontaram para a mudança de concepção dos sujeitos, em relação ao erro, possibilitando que fosse aceito de forma natural, sendo investigado pelas crianças e pela professora, num exercício de autorregulação. Outrossim, o jogo favoreceu a prática reflexiva e a participação crítica como norteadoras da aprendizagem matemática.

Palavras-chave: Avaliação formativa; Jogo; Aprendizagem matemática; Lúdico.

9 Esse artigo é parte da dissertação de mestrado da primeira autora, cujo projeto de pesquisa foi aprovado pelo Comitê de Ética em Pesquisa em Ciências Humanas e Sociais da Universidade de Brasília - CEPCHS, sob o n 2.997 .952$. 


\title{
The game as an evaluating procedure for Mathematical learning
}

\author{
Meire Nadja Meira de Souza \\ Geraldo Eustáquio Moreira
}

\begin{abstract}
This paper presents the challenge of investigating the potential of the game as a formative assessment procedure for mathematical learning. The study has a qualitative approach with participant observation delimited by the case study of six students, in the scenario of a public school in Ceilândia - Federal District, seeking to answer the problem: how to make the game an evaluative procedure that promotes mathematical learning in a 3 rd grade class elementary school year? The case study provided the opportunity to use different sources of evidence: participant observation, audio and video records during game propositions, and the field diary. The relevance in promoting formative assessment in the context of games lies in the fact that its playful potential provides possibilities for the elaboration of learning and constitutes a challenge that stimulates the construction of mathematical concepts. The research sought to place students as protagonists of their own learning, favoring to spontaneously manifest the knowledge built during the classes. The theoretical support provided thinking about the importance of the game in the production of mathematical knowledge considering the practice of feedback, by the teacher and peers, as an important instrument of activation of cognitive and metacognitive processes. The results pointed to the change of conception of the subjects in relation to the error, allowing it to be accepted in a natural way, being investigated by the children and the teacher, in an exercise of self-regulation. Moreover, the game favored reflective practice and critical participation as guiding mathematical learning.
\end{abstract}

Keywords: Formative evaluation; Game; Mathematical learning; Ludic. 


\section{Introdução}

Ao longo dos anos, a avaliação vem estabecendo-se como campo cheio de peculiaridades que constitui o universo educacional, dentre outros aspectos. O entendimento de avaliação que, teoricamente, garante também a autoavaliação, ainda é confundido com provas e exames, prevalecendo, assim, as avaliações somativas e excludentes que visam o produto final e desconsideram o processo de aprendizagem. Essa compreensão equivocada desconsidera o que preconizam as Diretrizes de Avaliação Educacional: a avaliação não deve se resumir à aplicação de testes ou exames, tampouco se confunde com medida (DISTRITO FEDERAL, 2014).

Pesquisadores e autores como Carvalho (2009), Fernandes (2009) e Perrenoud (1999) têm discutindo as diferentes funções das avaliações, que se materializam na escola sob a forma de provas, exames, trabalhos em grupos, dramatizações, autoavaliação, entre outras. Para estes estudiosos, o termo feedback refere-se ao retorno ou à devolutiva para o aluno. Assim, sua intenção é a de que o aprendiz reflita e faça melhor numa próxima atividade, não cabendo, portanto, outro uso para esse recurso e menos ainda o sarcasmo ou a ironia, tão difundidos nos últimos anos e compartilhados nas redes sociais como forma de humilhação e crítica aos erros cometidos por estudantes em suas avaliações institucionais realizadas nos diversos níveis de ensino.

As atividades lúdicas também estão presentes em nossa vida diária e, de acordo com a BNCC (BRASIL, 2018), devem perpassar todas as áreas do conhecimento, especialmente, nos Anos Iniciais, onde a articulação com as experiências lúdicas vivenciadas na Educação Infantil é primordial para a criança.

Jogos e brincadeiras atraem crianças e adultos, mas especialmente durante a infância, são imprescindíveis para o desenvolvimento dos pequenos. As brincadeiras favorecem a interação entre pares e, nesses momentos, há aprendizagens significativas porque partem da experimentação e da vivência. Por sua vez, os jogos oportunizam possibilidades de elaboração de aprendizagens, exploradas de acordo com as potencialidades que cada um oferece e se constituem em desafios que estimulam a construção de conceitos matemáticos.

Nesse sentido, os jogos são considerados, aqui, como procedimentos de aprendizagem, conforme observou Starepravo (2009, p. 28), "quando as crianças criam seus próprios procedimentos, sabem explicar o que fizeram, bem como argumentar sobre o caminho escolhido, aprendendo a pensar por si mesmas, sem esperar que alguém lhes mostre como fazer ou oferecendo um modelo”. Dessa forma, quando os estudantes explicam os procedimentos adotados, retornando ao que pensaram, estão construindo os processos de 
autorregulação e ativando os processos de metacognição ${ }^{10}$, tão importantes para a aprendizagem.

Consentaneamente, Muniz (2010, p. 126) apresenta o metajogo como uma etapa posterior, na qual são levantadas questões que conduzem às discussões "e o pensar sobre o pensamento presente no jogo".

Carraher, Carraher e Schliemann (2011) afirmaram ter presenciado nas escolas uma representação social da Matemática como uma área do conhecimento elitizada, com acesso para poucos. Sandes e Moreira (2018, p. 100-101) questionam “como é possível uma prática docente assentada na Educação Matemática, na sociedade contemporânea, em que há diversas inovações tecnológicas e que podem, de algum modo, ser mais atrativas para o aluno do que a própria sala de aula?”. Para os autores, “essa prática docente, seguramente, deverá contemplar aprendizagens significativas e, também, permitir ao aluno utilizar esses ensinamentos em sua vida cotidiana, de maneira objetiva e útil.” (p. 101).

Mas essa Matemática - a escolar - é alicerçada em estratégias e não na basilar construção de conceitos, pois muitos dos que não a fazem na escola, utilizam-se dela na vida diária, vendendo, comprando, medindo e calculando. Dessa forma, percebemos que muitas vezes os saberes escolares são vazios de sentido para os estudantes, impedindo-os de estabelecer ligação entre os saberes da sua vida cotidiana e, por conseguinte, dificultando a explicitação do seu conhecimento a partir dos instrumentos avaliativos propostos. Nesse sentido, Fernandes (2009, p. 30) mencionou resultados de uma pesquisa internacional que revela a possibilidade de "fazer melhor, quer em nível das práticas que se desenvolvem nas salas de aula e nas escolas, quer em nível da chamada avaliação em larga escala [...].

Destarte, a proposta desta pesquisa encontra relevância ao promover a avaliação formativa a partir do potencial lúdico que os jogos oportunizam, favorecendo a elaboração de aprendizagens e se constituindo em desafio que estimula a construção de conceitos matemáticos, porque o "investimento na formação especializada de professores seja em nível médio ou superior", necessariamente, “deve ser pensado como preparação fundamental à compreensão das dinâmicas de aprendizagem e da complexidade das relações no espaço educativo" (TEIXEIRA; PAIVA; MOREIRA, 2018, p. 393).

\section{Avaliar para as aprendizagens}

Sabe-se que a avaliação é um instrumento de verificação do ensino e da aprendizagem (FERNANDES, 2009) e que situações declaradas de avaliação, teste, prova ou exame, independentemente da terminologia utilizada, geralmente causam ansiedade, inibição e medo.

${ }^{10} \mathrm{O}$ termo metacognição, no sentido etimológico, refere-se à capacidade de conhecer o próprio ato de conhecer. 
Assim, a relação entre avaliador e avaliado pode interferir nos resultados dos exames e mascarar a real capacidade dos estudantes. Por outro lado, quando é utilizada com o objetivo de avaliar para as aprendizagens, possibilita a promoção de intervenções que facilitam a construção do conhecimento. Assim, a avaliação não deve ser um fim, mas um meio para o estudante construir seu conhecimento e um meio para o professor planejar e ressignificar suas práticas pedagógicas, numa lógica de ensino-aprendizagem, com professores e estudantes ensinando e aprendendo juntos.

O processo de avaliação, segundo Carvalho (2009), faz parte do cotidiano e da realidade do ser humano, constituindo-se como uma característica natural deste que seleciona e faz escolhas constantemente para a tomada de decisões. No meio educacional, a avaliação faz parte da realidade de professores, estudantes, pais, gestores e coordenadores, além da sociedade em geral.

Com a função de orientar os processos de aprendizagem, a avaliação apresenta três níveis: aprendizagem, no âmbito da sala de aula; institucional, na esfera escolar; e avaliação em larga escala, abrangendo as redes de ensino. Freitas et al. (2009, p. 18) ressaltam que os três níveis devem caminhar juntos: ao enfatizar a sala de aula é preciso lembrar que ela está inserida na escola, que por sua vez faz parte de um sistema.

Enquanto incorpora a função social de exclusão, a escola utiliza os procedimentos avaliativos para punir aqueles que não se encaixam em seus moldes pré-estabelecidos, prejudicando a emancipação dos sujeitos no âmbito escolar e colaborando para que fora dele, sejam passivos e dependentes, incapazes de modificar a realidade na qual estão inseridos.

Luckesi (2011) constata que a escola pratica mais exames que avaliação e diferencia os termos ao afirmar que os exames estão voltados para o passado, presos aos problemas e ao produto final. Dessa forma, a realidade é simplificada e o educando tem seu desempenho examinado de forma pontual, classificatória, celetista, antidemocrática e autoritária. Em contrapartida, o autor assevera que a avaliação é construtiva, diagnóstica, inclusiva, democrática e dialógica. Outrossim, está voltada para o futuro, focada na solução, no processo e no produto, simultaneamente, que culminará no resultado, considerando a "complexidade das variáveis que interferem no processo de ensino-aprendizagem e nos próprios atos de testar a aprendizagem dos educandos" (LUCKESI, 2011, p. 189).

Perrenoud (1999, p. 101) corrobora para a necessidade de uma avaliação formativa que "ajuda o aluno a aprender a se desenvolver, ou melhor, que participa da regulação das aprendizagens e do desenvolvimento no sentido de um projeto educativo".

Na concepção formativa, o aluno aprende a se desenvolver a partir das intervenções, com isto, todos devem ser avaliados e não só o estudante. Nesse sentido, o par objetivos/avaliação conduz o par conteúdos/forma porque orienta todo o processo e possibilita criar outras formas e estratégias de autoavaliar-se e repensar o planejamento de modo a 
conduzir a aula (FREITAS, 1995). Do mesmo modo, o par conteúdos/forma, permite reformular e repensar que objetivos realmente se quer alcançar e de que forma será a avaliação. Assim, conhecer os objetivos da escola favorece o desenvolvimento do trabalho do professor e de outros profissionais que anseiam por uma escola com menos desigualdades sociais.

Segundo Villas Boas (2008), alguns instrumentos e procedimentos potencializam práticas de avaliação formativa: avaliação por pares; provas; portfólio; registros reflexivos; seminários; pesquisas e autoavaliação. Mas independente do instrumento, a avaliação deve ter o papel de mediar o conhecimento. Nesse sentido, Hadji (2001) pontuou que o formativo não depende do instrumento, mas da intenção do professor e o uso que ele faz desses instrumentos. O autor defendeu, em seus estudos, que a avaliação atua como um elemento a serviço das aprendizagens, possibilitando compreender a situação do aluno, equacionando o seu desempenho, alimentado por indicações dadas pelo docente que façam o educando prosseguir e não retroceder.

Destarte, a participação dos estudantes é fundamental no processo de avaliação formativa, cabendo ao professor a inserção de atividades avaliativas que preveem essa atuação inclusiva de forma a contribuir para que os alunos busquem nessas ações, formas de modelar os seus estilos intelectuais e hábitos de estudo, isto é, aprender a autoavaliar-se. Moreira e Manrique (2014, p. 132-133) asseveram que os aspectos sociais da aprendizagem inclusiva são evidenciados na "abordagem educacional que prioriza a interação do sujeito com o outro e com o meio social”.

Toledo e Toledo (2010, p.11), reconhecem o educando como agente, e concluem que "devemos atribuir a ele esse mesmo papel no que se refere à avaliação de sua aprendizagem". Os autores defendem que "é com a vivência de situações de reflexão sobre a própria aprendizagem" que os estudantes vão perceber onde e porque erraram, o que ainda não compreenderam do assunto, quando devem pedir ajuda do professor, entre outras questões.

Estes questionamentos podem nortear a autoavaliação que acontece em decorrência do feedback realizado e essa devolutiva deve ser específica, descritiva e não avaliativa, ou seja, deve servir para que o aluno reflita e faça melhor numa próxima atividade. A mera explanação do conteúdo ou de como se faz certa atividade não configura feedback, sendo necessário ter novos questionamentos, novas abordagens e mobilizar processos metacognitivos. O feedback deve ser compatível com o desempenho do aluno, como um parecer do trabalho realizado e precisa ser feito sem adiamentos pois quando é muito tardio, não tem mais serventia para a atividade produzida. Nas turmas de alfabetização, enquanto as crianças ainda estão se apropriando do sistema de escrita alfabética, a devolutiva oral é a mais utilizada podendo ser em grupo, em pares ou individual.

Nesse sentido, Brookhart (2008, p. 53) mencionou que "algumas maneiras comuns de oferecer feedback oral coletivo aos estudantes são no início de uma aula; partindo da aula 
anterior; no início de uma revisão; durante apresentações dos alunos e na devolutiva de testes e provas, destacando pontos fortes e fracos”. Dessa forma é possível tirar dúvidas, promover a troca de experiências a partir da socialização dos diferentes algoritmos encontrados pelos estudantes e sanar possíveis equívocos nas resoluções de situações problemas.

Durante as devolutivas das avaliações, é importante promover o feedback oral de forma individual e particular, especialmente quando se tratar de estudante com baixo rendimento escolar, evitando assim sua exposição e possível constrangimento diante dos colegas. Esse retorno às aprendizagens deve ser apoiado no diálogo e no acolhimento.

Dessa forma, cabe ao professor promover a inclusão de todos os estudantes para que coletivamente encontrem novos caminhos e juntos partilhem suas aprendizagens. Os jogos podem ser aliados nessa promoção porque enquanto jogam ou brincam as crianças alcançam aprendizagens efetivas que favorecem a autoavaliação e o feedback entre pares, seja quando retomam as regras ao perceberem que algum colega tentou burlar os acordos estabelecidos, seja quando justificam seus registros de pontuação na atividade, ou ainda quando questionam determinado procedimento no jogo. Muniz (2010, p. 126) assevera que, a partir da discussão, os problemas e processos são validados no grupo e a "atividade matemática” é desenvolvida, refletindo a "natureza da ação do espírito que está brincando".

\section{O jogo como possibilidade lúdica de avaliação}

Luckesi (2016) evidencia a importância dos jogos e brincadeiras para a construção das habilidades internas do sujeito e seu consequente desenvolvimento, podendo constituir-se em atividades lúdicas a depender do envolvimento dos sujeitos. Portanto, a atividade lúdica é aquela que propicia a plenitude da experiência e, ao contrário do que muitos acreditam, nem sempre é divertida, pois é um fenômeno interno de cada um.

O desenvolvimento da capacidade de lidar com conflitos, a expansão e o fortalecimento dos sentidos e da coordenação motora, ocorrem com o brincar e com o jogar que, além do mais, estimulam a criatividade e incentivam a socialização. Ademais, os jogos apresentam desafios que ajudam professores e educandos a saírem da sequência linear de conteúdos e a resolver problemas não convencionais, imersos em circunstâncias concretas ao invés das cansativas listas de exercícios descontextualizadas e insignificantes. Nesse sentido, Nacarato, Mengali e Passos (2009, p. 37) evidenciam a importância de que "a matemática seja para todos", privilegiando-se o pensamento conceitual e procedimental, tendo o estudante como sujeito que comunica suas ideias matemáticas e a escola com instituição que extrapola os modelos padrões de problemas com uma única resposta.

Jogar é uma atividade espontânea para as crianças, devido à sua não-obrigatoriedade, ainda que tenha regras. A partir do jogo, o estudante pode demonstrar naturalmente as aprendizagens e dificuldades e o professor, diante da observação do que o aluno exteriorizou, 
pode planejar e elaborar as intervenções necessárias para sua aprendizagem. A relevância em considerar esse recurso no contexto das avaliações, reside no fato de que "a utilização do jogo potencializa a exploração e a construção do conhecimento, por contar com a motivação interna, típica do lúdico" (KISHIMOTO, 2011, p. 42). Destarte, percebe-se nessa motivação interna a oportunidade de o estudante externar, de forma espontânea, sua aprendizagem, seja durante o jogo ou após seu término.

Vigotski (2003, p. 107) ajudou a compreender que os obstáculos que surgem durante o jogo colaboram na construção de pensamentos em busca de soluções e assinala que "para a criança, o jogo é a primeira escola de pensamento. Todo pensamento surge como resposta a um problema, como resultado de um novo ou difícil contato com os elementos do meio".

Em relação ao jogo, Muniz (2010), mencionou que este pode ser um mediador entre o sujeito que aprende e o conhecimento matemático na medida em que se percebe, a partir dele, a capacidade do sujeito de raciocinar, comunicar e transitar entre as muitas dimensões do conhecimento matemático. Ao assumir a função pedagógica, o jogo caracteriza-se como um procedimento de intervenção no processo de ensino e aprendizagem e, dessa forma, por meio do jogo, o professor pode avaliar as aprendizagens adquiridas, os obstáculos epistemológicos, didáticos, psicológicos (BROUSSEAU, 2008), que se apresentam.

Conforme princípios apresentados na BNCC (BRASIL, 2013, p. 265), a Matemática é elemento essencial na construção da cidadania e precisa ser acessível a todos, "seja por sua grande aplicação na sociedade contemporânea, seja pelas suas potencialidades na formação de cidadãos críticos, cientes de suas responsabilidades sociais”. Por isso, o trabalho docente deve objetivar, sobretudo, a democratização do seu ensino.

Os jogos podem ser aliados nessa promoção porque oportunizam a diminuição das assimetrias cognitivas (KISHIMOTO, 2011). Enquanto jogam ou brincam as crianças alcançam aprendizagens efetivas que favorecem a autoavaliação e o feedback entre pares, seja quando retomam as regras ao perceberem que algum colega tentou burlar os acordos estabelecidos, seja quando justificam seus registros de pontuação na atividade, ou ainda quando questionam determinado procedimento no jogo. Dessa forma, percebemos que o jogo, além de unir o aprendiz e o conhecimento, oferece a possibilidade de proporcionar experiências lúdicas e ainda oportuniza ao professor, promover práticas diferenciadas de avaliação.

De acordo com a BNCC (BRASIL, 2018, p. 278), os jogos estão entre os recursos didáticos que favorecem “a compreensão e utilização das noções matemáticas”, com a necessária formalização do conhecimento que vai da análise reflexiva à sistematização.

\section{Trajetória e metodologia da pesquisa}

Os procedimentos adotados para investigação abrangeram a abordagem qualitativa com caráter exploratório e interventivo, possibilitando a proposição investigativa de oferecer 
aos sujeitos, novas possibilidades avaliativas a partir de um contexto lúdico que favorecesse o desenvolvimento de competências no campo da Matemática. Com esse propósito, foi realizado um estudo de caso com seis estudantes do $3^{\circ}$ ano do Ensino Fundamental de uma escola pública de Ceilândia - Distrito Federal (SOUZA, 2018). O estudo de caso oportunizou a análise profunda da problemática e propiciou a utilização de diferentes fontes de evidência, quais sejam, a observação participante, os registros de áudio e vídeo durante as proposições dos jogos e o diário de campo.

A pesquisa teve início no mês de setembro de 2018, a partir da observação participante que durou três semanas. O objetivo inicial foi estabelecer maior aproximação com os sujeitos, cujos critérios de escolha foram definidos com base na igualdade de gênero e envolvimento com jogos. Foram selecionados dois estudantes com baixo rendimento escolar, dois com rendimento escolar mediano e dois com alto aproveitamento escolar. A seleção dos estudantes teve início com a análise de relatórios avaliativos dos bimestres anteriores, em concordância com a professora regente.

A partir da observação buscou-se compreender os procedimentos resolutivos das crianças e as evidências para suas aprendizagens matemáticas. Portanto, foram observados o envolvimento e as reações dos estudantes diante das atividades propostas pela professora bem como a comunicação e interação estabelecidas entre os colegas e a docente. Para melhor compreensão e análise, as crianças foram observadas no grupo e individualmente, de acordo com suas especificidades.

Os jogos propostos durante a pesquisa foram: Conquistar e colorir (desenvolvido pelos pesquisadores), Quem ganha mais (desenvolvido pela pesquisadora) e Quantos palitos? (adaptado com base no jogo Quantos palitos guardei?). Eles envolviam as ideias do campo multiplicativo e foram escolhidos de acordo com os objetivos do currículo previsto para o $3^{\circ}$ ano, em consonância com o planejamento do segundo semestre da professora regente. Cada jogo foi aplicado, pelo menos, três vezes na mesma semana, conforme planejamento com a professora regente, que se apropriava anteriormente do jogo para que junto à pesquisadora, participasse das intervenções com as demais crianças no momento da aplicação dos jogos. As ações foram gravadas em áudio e vídeo e com registros escritos no caderno de campo da pesquisadora.

A primeira aplicação ocorreu para que as crianças se apropriassem do jogo e de suas regras e para que se motivassem a participar da experiência com proposta lúdica. Durante a segunda aplicação, além de fazer as adaptações necessárias no jogo, a pesquisadora instigou a resolução das situações problemas que surgiram, avaliando as aprendizagens já consolidadas pelas crianças e buscando foco nos sujeitos da pesquisa. Naquele momento foram observadas a comunicação, o envolvimento com o jogo e as estratégias utilizadas pelas crianças. 
Por fim, o metajogo foi proposto a partir da devolutiva dos registros às crianças, buscando a construção dos processos de metacognição com a projeção de imagens e degravação de trechos de falas dos colegas nos momentos dos jogos.

O metajogo, segundo Muniz (2016, p. 34), apresenta-se como uma das possibilidades de mediar a aprendizagem, a partir do jogo. O metajogo ocorre com a "realização de um debate sobre o jogo espontâneo após a realização da atividade lúdica”. Nesse sentido, após jogarem, o professor anima um debate sobre a atividade. Segundo o autor, as justificativas, argumentações e provas fundamentam a geração de atividade matemática. Ademais, favorecem um retorno às jogadas, às falas e aos pensamentos ocorridos no jogo, para validação de algumas ações matemáticas que, em muitos casos, passam desapercebidas pelas crianças por estarem envolvidas pela energia lúdica.

\section{Organização dos dados}

Todo o material gravado em áudio e vídeo, após degravação, bem como as fotografias e os registros escritos da pesquisadora e dos alunos foram preparados, organizados e catalogados. Em seguida foi realizado o recorte dos conteúdos para a devida ordenação e análise.

A análise dos dados construídos pautou-se em alguns elementos da Análise de Conteúdo de Bardin (2016) cujas diretrizes estabelecidas são: a pré-análise, a exploração do material e o tratamento dos resultados encontrados, que envolve a inferência e a interpretação.

Segundo Bardin (2016, p. 125), na pré-análise ocorre a organização. Seu objetivo é "tornar operacionais e sistematizar as ideias iniciais, de maneira a conduzir a um esquema preciso do desenvolvimento das operações sucessivas [...]”. Essa é a fase da seleção dos documentos que serão analisados, a formulação das hipóteses - de caráter não obrigatório - e a criação de indicadores que justifiquem a interpretação dos resultados. A segunda fase, "longa e fastidiosa” (BARDIN, 2016, p.131) corresponde à exploração do material selecionado na fase anterior.

Neste artigo, tomaremos para análise a proposição do jogo Quantos palitos? cujos objetivos foram:

- Aprofundar o conceito de multiplicação a partir de jogos;

- Levantar hipóteses sobre as possibilidades de multiplicação;

- Fixar os fatos da multiplicação e,

- Desenvolver atitudes de interação, colaboração e troca de experiências em grupo.

O quadro 1 apresenta os materiais e as regras do jogo proposto. 
Quadro 1: Regras do jogo e materiais utilizados.

\begin{tabular}{|l|}
\hline Materiais: \\
- 100 palitos para cada grupo; \\
- 10 caixinhas vazias de fósforo para cada grupo; \\
- Fichas para registro da pontuação; \\
- 2 dados numéricos de 1 a 10 \\
Regras do jogo: \\
Após decidir quem iniciará o jogo, a primeira equipe jogará um dado para saber quantas \\
caixas deverá pegar e o outro dado para saber a quantidade de palitos em cada caixa. Em \\
seguida, cada jogador representará a quantidade utilizando caixas e palitos e um membro \\
da equipe fará a pergunta aos demais grupos: Quantos palitos nas caixas? \\
Todas as equipes deverão calcular e escrever na ficha, a quantidade total de palitos \\
guardados. Após conferir e justificar os resultados, as equipes que acertarem, marcarão a \\
quantidade de pontos conforme o resultado, se não acertar, o ponto será somente da equipe \\
que fez a pergunta, desde que responda corretamente. \\
Sempre que necessário, os jogadores poderão contar os palitos para conferir a \\
multiplicação. Vencerá o jogo, a equipe com maior pontuação ao final das rodadas. (Cada \\
equipe jogará os dados uma vez, totalizando o número de rodadas conforme a quantidade \\
de equipes.)
\end{tabular}

Fonte: Arquivo dos pesquisadores

A execução desdobrou-se em três momentos distintos de aplicação, sendo o primeiro para conhecer, vivenciar e apropriar-se do jogo, o segundo para fazer os ajustes que a primeira aplicação exigiu, a exemplo da ficha de registro e dos dados para definir a quantidade de caixas e palitos, e por fim, o terceiro momento para o metajogo, onde as crianças tiveram a oportunidade de refletir sobre o jogo e seus registros durante a atividade.

No jogo Quantos palitos, os estudantes determinavam quantas caixas (de um total de dez) e quantos palitos (de um total de 100) e construíam a situação para o outro jogador, desafiando-o a descobrir quantos palitos no total. Já nessa primeira aplicação, as crianças pediram folhas para registrarem seus pontos ou para desenhar os palitinhos. Essa primeira versão comprometeu a dimensão lúdica do jogo porque, no anseio de dificultar a questão para o colega, as crianças propuseram situações que exigiam representações mais complexas, com mais de 20 palitos em cada caixa. Rapidamente as crianças perderam o interesse pelo jogo porque cada jogada demorava muito para ser finalizada, conferida e pontuada, gerando tempo ocioso para os demais que aguardavam.

O jogo foi reestruturado pela pesquisadora, com a inclusão de dois dados. Então, a partir da segunda aplicação, as crianças jogavam dois dados com dez faces de um a dez: o primeiro dado determinava quantas caixas deveriam pegar e o segundo dado determinava quantos palitos colocariam em cada uma, resultando na soma de parcelas iguais. A inserção dos dados foi importante para garantir a imprevisibilidade e dar mais dinâmica ao jogo. As crianças apoiavam suas contagens na utilização dos palitos e cada partida tinha a pontuação correspondente ao total de palitos, conforme determinado pelos dados. As respostas eram conferidas pelos colegas que comparavam resultados e todos que alcançassem a resposta correta marcavam pontos. Ganhava o jogo quem conseguisse a maior pontuação. 
A partir da necessidade do grupo, o registro escrito passou a fazer parte das regras do jogo, seja para registrar as jogadas ou para facilitar as contagens, como se observa na figura 1.
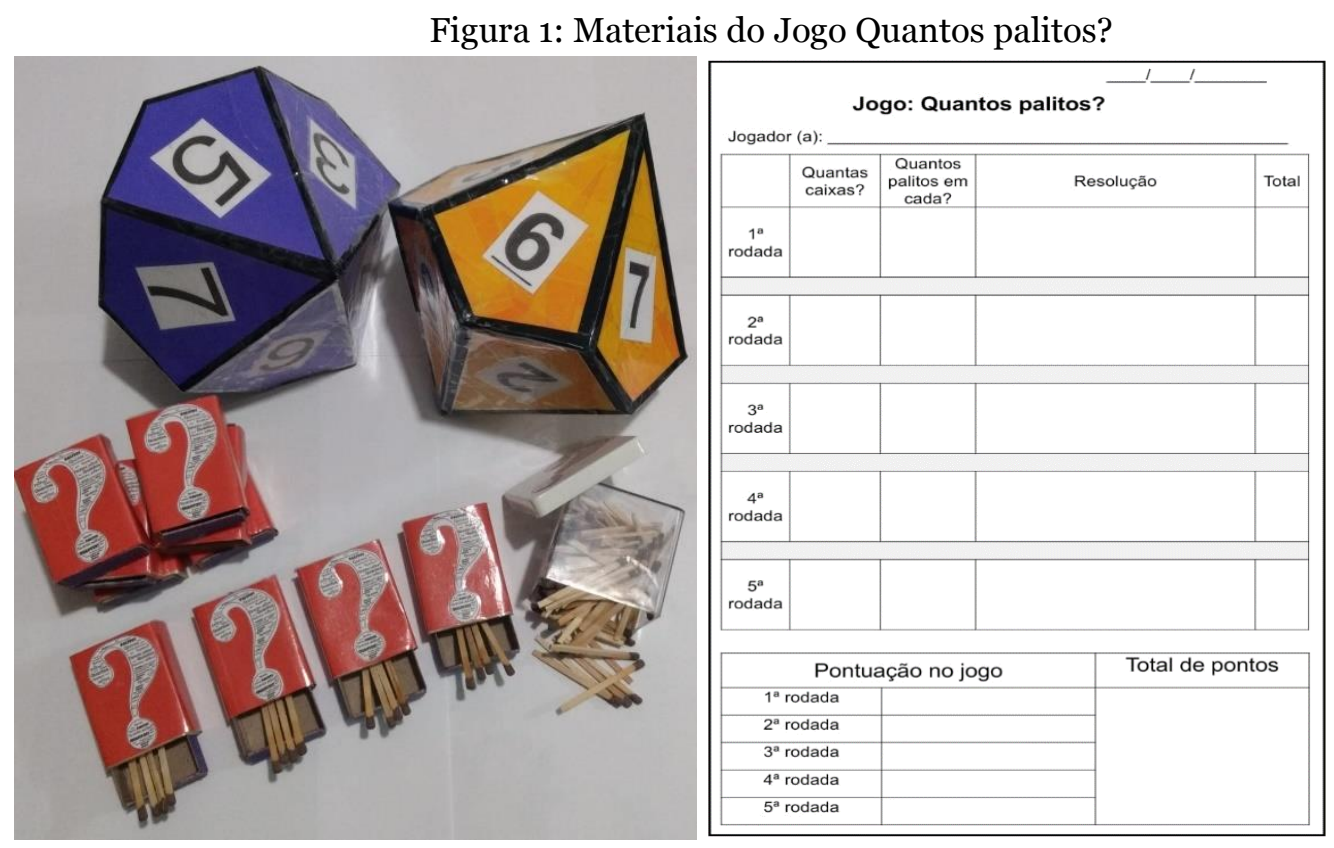

Fonte: Arquivos dos pesquisadores

Para desenvolver a autoavaliação e o feedback entre pares, realizamos o metajogo durante as jogadas e após seu término, favorecendo aos estudantes a retomada das regras e instigando entre eles a ocorrência de questionamentos sobre seus registros, estratégias e procedimentos. O metajogo, conforme Muniz (2010, p. 127), favorece o debate que "pode gerar atividade matemática fundada no processo de justificação, argumentação e prova”. Essa prática oportuniza a ocorrência da metacognição.

\section{Resultados e análises}

Durante a observação, foram encontrados distintos achados, dentre os quais, a percepção de lacunas na alfabetização tanto em língua materna quanto em linguagem matemática. Notou-se que as crianças com maiores dificuldades/defasagens na aprendizagem sentavam-se mais próximas da lousa e da professora. Durante as aulas a turma era organizada em duplas ou em grupos de quatro a cinco componentes. Essa disposição favoreceu o diálogo e a interação entre os estudantes bem como a socialização das aprendizagens.

As observações evidenciaram os sujeitos da pesquisa, mas também o comprometimento da professora com a aprendizagem dos estudantes e com sua própria formação inicial e continuada, que ainda é muito deficitária. Os entraves no ensino e na aprendizagem revelaram, entre outros aspectos, a urgência de uma formação inicial adequada e a importância da formação continuada dentro e/ou fora do espaço escolar que, muitas vezes, 
configura-se como único recurso para o preparo e auxílio ao professor que está em sala de aula, em especial àqueles com pouca ou nenhuma experiência docente.

Nessa perspectiva, Moreira (2019, p. 55) reforça que, na atualidade, o professor "deve ser concebido como um profissional que está em constante formação e que precisa estar apto a investigar os saberes necessários para lidar com as situações cotidianas da sala de aula”. Esse panorama exige uma autoavaliação permanente da prática pedagógica docente.

A proposição de jogos teve início com a aplicação do primeiro jogo, Quantos palitos (Adaptado pela pesquisadora com base no jogo Quantos palitos guardei?) ${ }^{11}$ as crianças ficaram surpresas com a câmera e questionaram o motivo de sua inserção em sala. Após a explicação de que utilizaríamos as imagens para aprender como os colegas jogavam e quais as suas estratégias durante os jogos, consideraram um importante instrumento para a sala de aula. Às vezes até esqueciam que estavam sendo filmados, como no caso de alguns estudantes que durante as partidas dos jogos, trapacearam para obter alguma vantagem.

O jogo foi apresentado às crianças, a partir de um cartaz com as regras e os materiais necessários. O texto instrucional foi lido coletivamente e todo o grupo conversou sobre as regras. Nesse momento as dúvidas também foram esclarecidas. As crianças receberam uma cópia com as regras do jogo.

A cada partida, foram realizados feedbacks orais por equipe ou para toda a turma e, em alguns casos, as devolutivas orais foram individuais a exemplo do diálogo abaixo, cujo recorte, a partir das gravações em áudio e vídeo, apresenta o feedback dado à estudante $\mathrm{Y}$, conforme demonstrado na figura 2. Os nomes dos participantes foram substituídos por suas iniciais para assegurar a preservação de suas identidades.

É possível perceber que, quando a estudante afirma que faltaram dois, ela referia-se aos dois números quatro que ela não contou, totalizando $6 \mathrm{X} 4$ ao invés de $8 \mathrm{X} 4$. Observa-se, ainda, que a estudante "Y" fez a inversão da operação, que deveria ser 4 X 8. No entanto, ao ser confrontada com a situação-problema e sua resposta, a estudante percebe a inversão e corrige seu registro, operando "regulações intelectuais", conforme Perrenoud (1999, p. 96) ao asseverar que "na mente humana, toda regulação, em última instância, só pode ser uma autorregulação' ${ }^{12}$.

\footnotetext{
${ }^{11}$ Disponível em: http://portaldoprofessor.mec.gov.br/fichaTecnicaAula.html?aula=49879 Acesso em: 20 jul. 2018.

${ }^{12}$ Perrenoud (1999, p. 97) define autorregulação como as capacidades do sujeito de gerir seus progressos e estratégias diante das situações apresentadas.
} 
Figura 2: Transcrição do áudio do momento do feedback individual

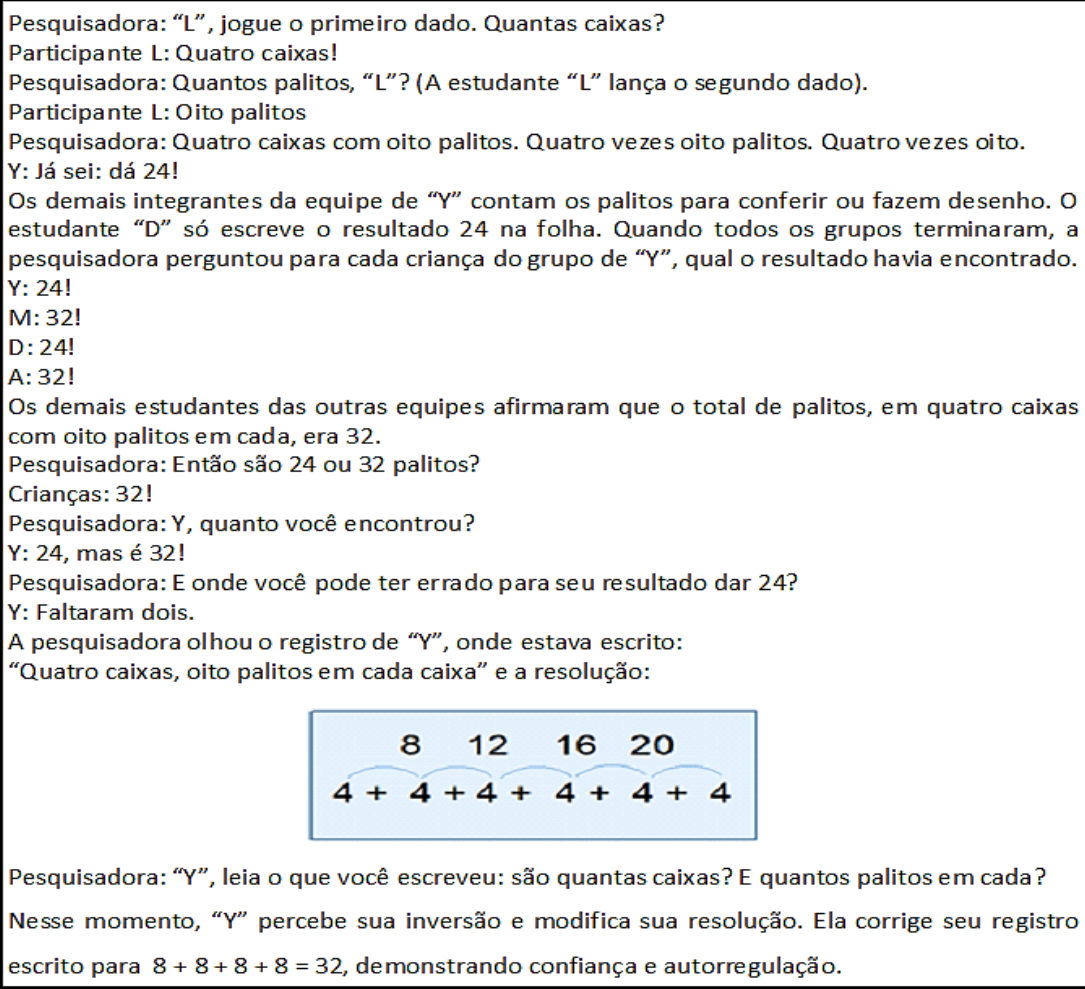

Fonte: Arquivos dos pesquisadores.

A figura 3 representa o registro escrito que favoreceu um momento de feedback oral em grupo, a partir da representação da estudante E:

Figura 3: Registro da estudante E.

\begin{tabular}{|l|l|c|}
\hline \multicolumn{2}{|c|}{ Pontuação no jogo } & Total de pontos \\
\hline $1^{\mathrm{a}}$ rodada & 45 & \multirow{2}{*}{$16^{5}$} \\
\hline $2^{\mathrm{a}}$ rodada & 54 & \\
\hline $3^{\mathrm{a}}$ rodada & 32 & \\
\hline $4^{\mathrm{a}}$ rodada & 16 & \\
\hline $5^{\mathrm{a}}$ rodada & 16 & \\
\hline
\end{tabular}

Fonte: Arquivos dos pesquisadores

A estudante "E" explicou como havia resolvido essa situação: somando todas as rodadas. No entanto, algumas crianças questionaram o resultado. O estudante " $D$ " disse que, da forma como os números estavam organizados, o resultado provável seria "duzentos e pouco". Questionado, afirmou que os algarismos 1 pareciam que estar na centena. A estudante "Y" considerou essa hipótese e resolveu a operação chegando ao total de 471, conforme figura 4:

Figura 4: Representação da resolução da estudante Y.

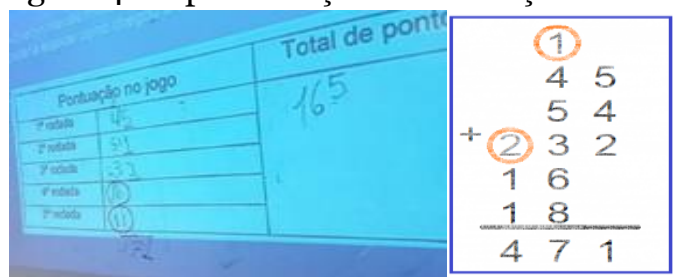

Fonte: Arquivos dos pesquisadores. 
Os diferentes pontos de vista das crianças foram importantes para que elas refletissem sobre os erros que cometem. No exemplo acima, foi possível perceber e analisar o que levou ao resultado encontrado por "Y". Starepravo (2009, p. 45) assevera que "quando entendemos os caminhos que nos levaram ao erro, nos apropriamos do conhecimento com mais consistência”.

Apesar de ter sido apenas uma provocação da estudante, tendo em vista que ela percebeu que os números apenas estavam, a seu ver, numa posição desfavorável para sua resolução, "Y" revelou sua compreensão de valor relativo ao considerar o 16 e o 18 como dezenas, a partir da posição que os números ocupavam na operação, pressupondo o espaço vazio à direita como zero. Depreende-se que o erro revela muito do que o estudante sabe, muitas vezes extrapolando os construtos avaliados.

Ao retomar a pontuação com seus valores originais, o estudante “D” propôs uma outra forma de resolução, conforme transcrição do áudio, na figura 5 .

Figura 5: Transcrição do áudio da resolução de uma operação Matemática.

D: Eu sei fazer outra conta.
O estudante vai até a lousa e resolve apontando para os números e afirmando: " 45 mais 54
dá 99.32 mais 16 dá 48 . E eu não sei o do $18 . "$
Pesquisadora: Então faz pra gente o que você pensou. Escreve aí no quadro.
O estudante registra: $99+48=147+18=165$
Pesquisadora: Alguém entendeu o que o " $D^{n}$ pensou?
M: Eu acho que ele fez duas contas em uma só.
Pesquisadora: Duas contas? Pode explicar como você fez, " $\mathrm{D}^{n} ?$
D: $45+54$ que deu 99.
D: $32+16$ que deu 48.
Pesquisadora: Por que 48 ?
D: dois mais seis dá oito e três mais um dá quatro.
Pesquisadora: E por que o "D" escreveu 147 ? Como você encontrou esse resultado?
D: É que eu vi que 99 estava perto do 100 . Juntei 100 com 48 e tirei um aí sobrou 147.
Pesquisadora: 99 para chegar no 100 , falta quanto?
Crianças: Um!
Pesquisadora: O "D" tirou um daqui do 48 . O 48 ficou com quanto?
Crianças: Com $47 !$
Pesquisadora: 100 mais 47 ?
Crianças: $147 !$
Pesquisadora: E como você fez essa conta aqui, " $D$ ": 147 mais $18 ?$
D: Eu juntei 140 mais 10 e deu 150 . Aí eu contei sete mais oito e deu 15 . Depois eu juntei
a dezena que formou, porque tem que ir para a dezena, e deu 160 . Então ficou 165 com
aquele cinco.

Fonte: Arquivos dos pesquisadores

O estudante "D" utilizou, com criatividade, um algoritmo diferente para resolver a situação que surgiu. O registro escrito é para ele, um desafio e motivo de tensão e angústia, porque ainda está se apropriando da escrita da língua materna e sente dificuldade também na grafia do número. No entanto, ele explicita seu registro mental e material no jogo expressando muita alegria em compartilhar sua descoberta.

Neste sentido, entendemos a Matemática, aqui defendida, na perspectiva de buscar uma educação crítica, "que discuta condições básicas para a obtenção do conhecimento, que esteja situada nos problemas sociais, por exemplo, nas desigualdades, e que tenha força social progressivamente ativa, reagindo às contradições sociais” (VIEIRA; MOREIRA, 2018). 


\section{Considerações finais}

A Matemática faz parte da vida de todas as pessoas e, na escola, é preciso que ela esteja presente de modo significativo, no desenvolvimento das habilidades intelectuais do indivíduo, na agilização de seu pensamento reflexivo-crítico, de seu raciocínio para aplicá-la nas diferentes situações que enfrenta, seja em casa, seja em sua comunidade.

Ao pensar e monitorar suas aprendizagens, o estudante desenvolve a consciência metacognitiva e a competência para supervisionar seu próprio trabalho além de ter a oportunidade de refletir sobre sua avaliação, sendo ele sujeito perante o saber.

Nessa perspectiva, identificamos algumas necessidades de aprendizagem dos estudantes que foram reveladas a partir do jogo, cujos registros, materiais e escritos, estão contribuindo para o metajogo. O diagnóstico da não aprendizagem deve servir à reorientação e não à justificação dos erros que não suprem a ignorância (LUCKESI, 2011). Assim, o diálogo e a prática de feedback favorecem a avaliação mediadora pois oportunizam momentos privilegiados de sondagem das aprendizagens que ocorreram ou não, quais dificuldades foram apresentadas e quais caminhos serão traçados para a construção de novos conhecimentos.

Dessa forma, concluímos que, se a criança aprende brincando, é possível ensiná-la utilizando-se de jogos, que podem se tornar procedimentos de avaliação. Se bem explorados, os jogos servirão como facilitadores na construção do conhecimento e também na explicitação do que a criança já sabe e onde precisa avançar, permitindo a obtenção de resultados positivos no seu processo de ensino e de aprendizagem de Matemática, uma vez que esta deve ter sentido prático na vida real do estudante, concedendo-lhe condições de aplicar o aprendido nas aulas de Matemática na vida real (MANRIQUE; MARANHÃO; MOREIRA, 2016a; b).

Os jogos oportunizaram a externalização dos processos de pensamento pela criança, deixando de fora a insegurança e o medo e evidenciando maior envolvimento e iniciativa dos participantes na expressão de suas ideias. Ademais, a avaliação, no contexto de jogos, favoreceu o letramento matemático pois contribuiu para que os estudantes compreendessem e empregassem a matemática em situações adversas. A pesquisa revelou que a afetividade é importante potencializadora das aprendizagens, pois é por meio dela que o professor reconhece cada estudante de forma particular e, assim, sabedor de suas necessidades, pode promover o melhor feedback, a melhor intervenção.

\section{Referências}

BRASIL. Base Nacional Comum Curricular: educação é a base. Ministério da Educação. Brasília, DF: 2018. Disponível em: http://basenacionalcomum.mec.gov.br/images/BNCC_EI_EF_110518_versaofinal _site.pdf Acesso em: 27 dez. 2018. 
BRASIL. Ministério da Educação. Secretaria de Educação Básica. Secretaria de Educação Continuada, Alfabetização, Diversidade e Inclusão. Secretaria de Educação Profissional e Tecnológica. Conselho Nacional da Educação. Câmara Nacional de Educação Básica. Diretrizes Curriculares Nacionais Gerais da Educação Básica. Brasília, DF: MEC, SEB, DICEI, 2013.

BROOKHART, S M. How to give effective to your students. Alexandria, VA: Association for Supervision and Curriculum Development, 2008.

BROUSSEAU, G. Introdução ao estudo das situações didáticas: conteúdos e métodos de ensino. São Paulo: Ática, 2008.

CARRAHER, T.; CARRAHER, D; SCHLIEMANN, A.. Na vida dez, na escola zero. 16 ed. São Paulo: Cortez, 2011.

CARVAlHO, M. B. Avaliação no mundo contemporâneo. In: A3 Metodologias de Avaliação e Construção de Indicadores. Rio de Janeiro: Editora Ciência Moderna, 2009.

DISTRITO FEDERAL. Secretaria de Educação. Diretrizes Pedagógicas para Organização Escolar do $2^{\circ}$ Ciclo para as Aprendizagens: BIA e $2^{\circ}$ Bloco. Brasília - DF, 2014.

FERNANDES, D. Avaliar para aprender: fundamentos, práticas e políticas. São Paulo: UNESP, 2008.

FREITAS, L. C. Crítica da organização do trabalho pedagógico e da didática. Campinas: Papirus, 1995. ., SORDI, M. R. L. de., MALAVASI, Maria Marcia Sigrist. \& FREITAS, Helena Costa Lopes de. Avaliação Educacional: Caminhando pela contramão. Petrópolis, RJ: Vozes, 2009.

HADJI, C. Avaliação desmistificada. Trad. Patrícia C. Ramos. Porto Alegre: Artmed, 2001. KISHIMOTO, T. M. (Org.). Jogo, Brinquedo, Brincadeira e a Educação. 14 ed. São Paulo: Cortez, 2011.

LUCKESI, C. C. Avaliação da aprendizagem: componente do ato pedagógico. São Paulo: Cortez, 2011.

. Ludicidade e atividades lúdicas: uma abordagem a partir da experiência interna. 2016. Disponível em: http://luckesioo2.blogspot.com/2016/o7/ Acesso em 14/07/2017.

MANRIQUE, A. L.; MARANHÃO, M. C. S. de Albuquerque; MOREIRA, G. E.. Desafios da Educação Matemática Inclusiva: Formação de Professores. Volume I. São Paulo: Editora Livraria da Física, 2016a.

. Desafios da Educação Matemática Inclusiva: Práticas. Volume II. São Paulo: Editora Livraria da Física, 2016b. 
MOREIRA, G. E.; MANRIQUE, A. L. Educação Inclusiva: representações sociais de professores que ensinam matemática. Poiesis Pedagógica. UFG, Catalão, 2014.

MUNIZ, C. A. Brincar e jogar: enlaces teóricos e metodológicos no campo da educação matemática. Belo Horizonte: Autêntica, 2010.

. Educação lúdica da matemática, educação matemática lúdica. In: SILVA, A. J. N. S.; TEIXEIRA, H. S. (Org.) Ludicidade, formação de professores e Educação matemática em diálogo. Curitiba: Appris, 2016. p. 17-46.

PERRENOUD, P. Avaliação: da excelência à regulação das aprendizagens - entre duas lógicas. Porto Alegre: Artes Médicas Sul, 1999.

SANDES, J. P.; MOREIRA, G. E. Educação Matemática e a Formação de Professores para uma prática docente significativa. Revista @mbienteeducação, v. 11, 2018. p. 99-109.

SOUZA, M. N. M. de. O jogo como procedimento de avaliação para as aprendizagens matemáticas relativas ao sistema monetário. 99 p. (Dissertação de Mestrado) - Faculdade de Educação, Universidade de Brasília, Brasília, 2018.

STAREPRAVO, A. R. Jogando com a matemática: números e operações. Curitiba: Aymará, 2009.

TEIXEIRA, C. de J.; PAIVA, T. F.; MOREIRA, G. E. Matemática e Inclusão: para além dos resultados. Revista da Sociedade Brasileira de Educação Matemática $R E M A T / S P$, v. 15, n. 20, 2018. p. 389-408.

TOLEDO, M. B. de A; TOLEDO, M. de A. Teoria e prática de matemática: Como dois e dois. São Paulo: FTD, 2010.

VIEIRA, L. B.; MOREIRA, G. E. Direitos Humanos e Educação: o professor de Matemática como agente sociocultural e político. Revista da Sociedade Brasileira de Educação Matemática - REMAT/SP, v. 15, n. 20, 2018, p. 548-564.

VIGOTSKI, L. S. Psicologia Pedagógica. Trad. Claudia Schilling. Porto Alegre: Artmed, 2003. 311p.

VILLAS BOAS, B. M. de F. Virando a escola pelo avesso por meio da educação. Campinas: Papirus, 2008.

\section{Agradecimento}

Agradecemos o apoio da Fundação de Apoio à Pesquisa do Distrito Federal - FAP/DF, financiadora do Projeto de Pesquisa "Formação do Professor de Matemática na Perspectiva da Educação do Campo: formação e prática docente, didáticas específicas de Matemática e acompanhamento da aprendizagem do aluno". Também agradecemos o apoio e incentivo do Grupo de Pesquisa Dzeta Investigações em Educação Matemática - DIEM. 


\section{Biografia Resumida}

Meire Nadja Meira de Souza: Licenciada em Pedagogia pela UnB (2004). É pós-graduada em Psicopedagogia Institucional pela UCB (2005) e Possui Mestrado em Educação, pela Universidade de Brasília - UnB, na linha de pesquisa Educação em Ciências e Matemática (2017), com interesse nos eixos da Aprendizagem Lúdica e Educação Matemática. Participa do grupo de pesquisa Dzeta Investigações em Educação Matemática - DIEM/UnB. É professora do Ensino Fundamental da Secretaria de Estado de Educação do Distrito Federal, atuando principalmente na alfabetização de crianças nos anos iniciais. Tem experiência na área de Educação, com ênfase em alfabetização.

Lattes: http://lattes.cnpq.br/1332761513306562

Contato: meire.nadja@hotmail.com.

Geraldo Eustáquio Moreira: Licenciado em Ciências, pela UEG (1996); em Matemática, pela UNOESTE (1999) e em Pedagogia, pelo Instituto Superior Fátima/DF (2013). É pós-graduado em Ensino da Matemática, pela UNICLAR (2000), mestre em Educação, pela UCB (2005) e Doutor em Educação Matemática, pela PUCSP (2012), com estágio Doutoral na Universidade do Minho (Portugal). Realiza Estudos Pós-Doutorais no Proped, na UERJ. É Professor Adjunto da Universidade de Brasília - UnB, atuando na Faculdade de Educação, no Departamento de Métodos e Técnicas, vinculado aos Cursos de Educação (Licenciatura) e é Professor/Pesquisador da Pós-Graduação, níveis Mestrado e Doutorado, do Programa de Educação (PPGE), onde desenvolve pesquisas assentadas na Linha Educação em Ciências e Matemática, relacionadas à Educação Matemática, à Matemática e à Educação. É líder do Grupo de Pesquisa Dzeta Investigações Matemáticas - DIEM/UnB.

Lattes: http://lattes.cnpq.br/8911881624400864

Contato: geust2007@gmail.com. 